\title{
A Novel Approach to Prepare Well-Defined Silica-Supported Polyoxometalate Species by Reaction with a Chlorinated Support
}

\author{
Eva Grinenval, Jean-Marie Basset, and Frédéric Lefebvre \\ Université Lyon 1, CPE Lyon, CNRS, UMR C2P2, LCOMS, Bâtiment CPE Curien, 43 Boulevard du 11 Novembre 1918, \\ 69616 Villeurbanne, France \\ Correspondence should be addressed to Frédéric Lefebvre; lefebvre@cpe.fr
}

Received 25 June 2013; Accepted 19 July 2013

Academic Editor: Emmanuel Guillon

Copyright (C) 2013 Eva Grinenval et al. This is an open access article distributed under the Creative Commons Attribution License, which permits unrestricted use, distribution, and reproduction in any medium, provided the original work is properly cited.

Polyoxometalates were grafted covalently on SBA-15 by a two-step procedure. The dehydroxylated mesoporous silica was first modified by reaction with methyltrichlorosilane in presence of triethylamine. The resulting solid was fully characterized and contained a mixture of mono- and digrafted species $(\equiv \mathrm{Si}-\mathrm{O})_{n} \mathrm{SiMeCl}_{3-n}$. These surface $\mathrm{Si}-\mathrm{Cl}$ bonds can react with lacunary polyoxometalates as in solution, yielding to a $\equiv \mathrm{Si}-\mathrm{O}-\mathrm{POM}$ linkage. However, solid state MAS NMR shows that only the digrafted species react with the polyoxometalate. This new grafting method opens the way to the synthesis of a new class of catalysts which could operate in solution without leaching.

\section{Introduction}

Polyoxometalates (POMs) form a class of inorganic compounds made of early-transition metals in their highest oxidation states [1]. POM-based materials are of increasing interest in many application fields ranging from medicine [2] to catalysis [3] and electronics [4] owing to their unique, versatile, and tuneable properties. POMs have received a particularly extensive attention in catalysis because of their acid-base and redox properties coming from their chemical composition. However, having recourse to a matrice is absolutely necessary to prepare POMs-based materials in order to enhance the availability of active sites. For this purpose, two main strategies are described in the literature $[5,6]$ : (i) a direct synthesis or one-pot synthesis involving the incorporation of POM units in a matrice which is carried out in situ using the sol-gel technique; (ii) a postsynthetic procedure, involving a multistep strategy in contrast with the previous one, which is usually performed by impregnation technique. The second approach is widely used due to its easy implementation but suffers from several drawbacks including the difficulty to achieve high POMs loadings without significant decrease in surface area and ordering, the loss of initial high dispersity of supported POM units via leaching or the loss of homogeneity due to minor changes in the structure. All these drawbacks lead to reduce both activity and stability of immobilized POMs.

In a previous article, the concepts and strategy of surface organometallic chemistry (SOMC) were used to circumvent these problems associated with a conventional impregnation technique [7]. Thus the interactions between POM units and the silica support were carefully controlled using anhydrous POMs and partially dehydroxylated silica to afford a POMsbased material with well-defined surface species including one species covalently linked to the silica support. Otherwise, the use of bare silica favours noncovalent species because in most cases the immobilization of POMs units is based on the protonation of surface silanols corresponding to an electrostatic approach. Covalent approach has been up to now held back by the small number of organic-inorganic POMs hybrids available and suitable grafting methods. Thus, we provide in this paper a method answering to the drawbacks of the postsynthetic procedure and combining the advantages of the one-pot synthesis procedure including both stability and uniform distribution of the active phase. This method relies on the SOMC approach using (i) silica modified by chemical functions used as anchor points and (ii) POMs hybrids tailored to needs, that is, bearing organic moieties. The SOMC 
strategy reported in this paper was developed upon the homogeneous reactivity of an organosilyl derivative of polyoxometalate described by Mazeaud et al [8]. In the literature, the syntheses of organosilyl derivatives of polyoxometalates had been described since 1979 [9]. The only known example of polyoxometalate functionalized with two silanol groups is based on the divacant Keggin structure $\left[\gamma-\mathrm{PW}_{10} \mathrm{O}_{36}\right]$. The hybrid anion bis(tert-butylsilyl)decatungstophosphate $\left(n-\mathrm{Bu}_{4} \mathrm{~N}\right)_{3}\left[\left(\gamma-\mathrm{PW}_{10} \mathrm{O}_{36}\right)(t-\mathrm{BuSiOH})_{2}\right]$ [8] has been synthesized through phase-transfer conditions by reaction of $t$ $\mathrm{BuSiCl}_{3}$ with $\mathrm{Cs}_{7}\left[\left(\gamma-\mathrm{PW}_{10} \mathrm{O}_{36}\right)\right] \cdot x \mathrm{H}_{2} \mathrm{O}$. This anion displays an "open-structure" with two $t$ - $\mathrm{BuSiOH}$ groups anchored to the $\left[\gamma-\mathrm{PW}_{10} \mathrm{O}_{36}\right]$ framework and linked by a relatively strong hydrogen bond. The obtained species reacts cleanly with $\mathrm{Me}_{2} \mathrm{SiCl}_{2}$ in homogeneous conditions to yield $\left(n-\mathrm{Bu}_{4} \mathrm{~N}\right)_{3}[(\gamma-$ $\left.\left.\mathrm{PW}_{10} \mathrm{O}_{36}\right)(t \text {-BuSiO })_{2}\left(\mathrm{SiMe}_{2}\right)\right]$ where the $t$-BuSi groups are linked to the capping group, $\mathrm{SiMe}_{2}$, through two siloxo bridges. Thus, to achieve the corresponding well-defined heterogeneous species, the preparations of both partially dehydroxylated and chlorinated silica support SBA-1 $5_{(500) /[\mathrm{SiCl}]}$ and POM hybrid bis(methylsilyl)decatungstosilicate (n$\left.\mathrm{Bu}_{4} \mathrm{~N}\right)_{4}\left(\gamma-\mathrm{SiW}_{10} \mathrm{O}_{36}\right)(\mathrm{MeSiOH})_{2}$ are reported and the proof of concept of grafting is demonstrated, opening up a new scope of possibilities in POMs-based materials.

\section{Experimental}

2.1. General Procedure for the Preparation of Starting Materials. Heteropolyacids were synthesized from sodium tungstate $\mathrm{Na}_{2} \mathrm{WO}_{4}$ (99+\%, Acros), sodium metasilicate $\mathrm{Na}_{2} \mathrm{SiO}_{3}$ (44-47.5\%, Acros), potassium chloride $\mathrm{KCl}$ (99+\%, Acros), potassium carbonate $\mathrm{K}_{2} \mathrm{CO}_{3}$ (99\%, Acros), hydrochloric acid (37\%, Aldrich), methyltrichlorosilane $\mathrm{MeSiCl}_{3}$ (99\%, Aldrich), and tetrabutylammonium chloride $n-\mathrm{Bu}_{4} \mathrm{NCl}$ ( $>99 \%$, Fluka). Acetonitrile, pentane, and triethylamine were purified according to published procedures, stored under argon and degassed prior to use [10]. $\mathrm{CD}_{3} \mathrm{CN}$ and $\mathrm{D}_{2} \mathrm{O}(\mathrm{SDS})$ were used as received.

All experiments concerning the preparation of the support oxide as well as the grafting reactions were carried out by using standard air-free methodology in argon-filled vacuum atmospheres glovebox, on a Schlenk line, or in a Schlenk-type apparatus interfaced to high vacuum line $\left(10^{-5}\right.$ torr $)$.

Elemental analyses were performed at the CNRS Central Analysis Department of Solaize or at the laboratory ICMUB of the University of Bourgogne at Dijon.

Infrared spectra were recorded on a Nicolet 5700-FT spectrometer by using an infrared cell equipped with $\mathrm{CaF}_{2}$ windows, allowing in situ studies. Typically, 32 scans were accumulated for each spectrum (resolution $1 \mathrm{~cm}^{-1}$ ).

The ${ }^{1} \mathrm{H}$ MAS, ${ }^{13} \mathrm{C}$ CP-MAS, and ${ }^{29} \mathrm{Si}$ CP-MAS NMR spectra were recorded on a Bruker DSX-300 spectrometer equipped with a standard $4 \mathrm{~mm}$ double-bearing probehead. Samples were introduced under argon in a zirconia rotor, which was then tightly closed. The spinning rate was typically $10 \mathrm{kHz}$. A typical cross-polarization sequence was used, with $5 \mathrm{~ms}$ contact time and a recycle delay of 1 to $4 \mathrm{~s}$ to allow the complete relaxation of the ${ }^{1} \mathrm{H}$ nuclei. All chemical shifts are given with respect to TMS, as an external reference.
2.2. Preparation of $S B A-15_{(\theta)}$. Mesoporous SBA-15 was synthesized using the nonionic triblock copolymer poly (ethylene glycol)-block-poly (propylene glycol)-block-poly (ethylene glycol) (Pluronic P123, molecular weight $=5800$, BASF) as a structure directing agent. In a typical synthesis, $4 \mathrm{~g}$ (0.69 mmol) of Pluronic P123 (template) was added to $150 \mathrm{~mL}$ of a solution of $\mathrm{HCl}$ at $\mathrm{pH}=1.5$. To the solution, $9.33 \mathrm{~g}(49.9 \mathrm{mmol})$ of tetraethyl orthosilicate (silica precursor, TEOS, 98\%, Aldrich) was added at room temperature with vigorous stirring. After stirring for $3 \mathrm{~h}$, a clear solution was obtained containing the hydrolyzed silica precursor in interaction with the template. The resulting mixture was heated at $60^{\circ} \mathrm{C}$ with vigorous stirring and $75.4 \mathrm{mg}(1.80 \mathrm{mmol})$ of $\mathrm{NaF}$ used as a catalyst was added. Directly after the addition of $\mathrm{NaF}$, a white precipitate appeared and the resulting mixture was left for $48 \mathrm{~h}$ at $60^{\circ} \mathrm{C}$. The solid product obtained was calcined at $500^{\circ} \mathrm{C}$ for $4 \mathrm{~h}$ to remove the triblock copolymer. The calcined product was dehydroxylated at $500^{\circ} \mathrm{C}$ under high vacuum $\left(10^{-5}\right.$ torr $)$ in order to obtain the SBA-15 ${ }_{(500)}$ (for $\mathrm{SBA}-15_{(\theta)}$ samples, $\theta$ corresponds to the temperature of dehydroxylation). The surface area and the size of the pores of the SBA- $15_{(500)}$ were determined by $\mathrm{N}_{2}$ BET measurement at $77 \mathrm{~K}$. After this treatment the specific area was about $1000 \mathrm{~m}^{2} \cdot \mathrm{g}^{-1}$ with an $\mathrm{OH}$ density of $1.4 \mathrm{OH} \cdot \mathrm{nm}^{-2}(2.340$ $\left.\mathrm{mmolOH} \cdot \mathrm{g}^{-1}\right)$. Solid state MAS ${ }^{1} \mathrm{H}$ NMR ( $\left.\delta \mathrm{ppm}\right): 1.8$ $(\equiv \mathrm{SiO} \underline{\mathrm{H}})$.

2.3. Modification of $\mathrm{SBA}-15_{(500)}$ by $\mathrm{CH}_{3} \mathrm{SiCl}_{3}$. A mixture of triethylamine $(1.3 \mathrm{~mL}, 9.3 \mathrm{mmol})$ in pentane $(30 \mathrm{~mL})$ and $\mathrm{SBA}^{-15_{(500)}}(0.8 \mathrm{~g}, 1.86 \mathrm{mmol}$ of $\equiv \mathrm{SiOH})$ was stirred at $40^{\circ} \mathrm{C}$ for 3 hours. The solution was then filtered and the resulting solid was stirred 3 hours at $40^{\circ} \mathrm{C}$ with methyltrichlorosilane $(1.2 \mathrm{~mL}, 10.2 \mathrm{mmol})$. After filtration the solid was washed 3 times with pentane and dried $15 \mathrm{~min}$ under vacuum $\left(10^{-5}\right.$ torr) at $25^{\circ} \mathrm{C}$ and 24 hours at $150^{\circ} \mathrm{C}$. The resulting solid referred to as SBA- $15_{(500) /[\mathrm{SiCl}]}$ is white. Solid state $\mathrm{MAS}{ }^{1} \mathrm{H}$ NMR $(\delta \mathrm{ppm}): 0.2\left[(\equiv \mathrm{SiO})_{2} \mathrm{Si}\left(\mathrm{CH}_{3}\right) \mathrm{Cl}\right]$; $-0.3\left[(\equiv \mathrm{SiO}) \mathrm{Si}\left(\mathrm{CH}_{3}\right) \mathrm{Cl}_{2}\right]$. CP-MAS ${ }^{13} \mathrm{C} \mathrm{NMR}(\delta \mathrm{ppm})$ : $2.7 \quad\left[(\equiv \mathrm{SiO}) \mathrm{Si}\left(\underline{\mathrm{CH}_{3}}\right) \mathrm{Cl}_{2}\right] ;-1.9 \quad\left[(\equiv \mathrm{SiO})_{2} \mathrm{Si}\left(\underline{\mathrm{CH}}_{3}\right) \mathrm{Cl}\right] . \quad \mathrm{CP}-$ MAS ${ }^{29} \mathrm{Si} \operatorname{NMR}(\delta \mathrm{ppm}):-14 \quad\left[(\equiv \mathrm{SiO}) \underline{\mathrm{Si}}\left(\mathrm{CH}_{3}\right) \mathrm{Cl}_{2}\right] ;-28$ $\left[(\equiv \mathrm{SiO})_{2} \underline{\mathrm{Si}}\left(\mathrm{CH}_{3}\right) \mathrm{Cl}\right]$. C $0.79_{\mathrm{wt}} \%, 2.72 \mathrm{Cl}_{\mathrm{wt}} \%$. Molar ratio is $\mathrm{Cl} / \mathrm{C} 1.16$.

2.4. Monitoring of $\mathrm{SiO}_{2-(500) /[\mathrm{SiCl}]}$ by In Situ Infrared Spectroscopy. Silica $(35 \mathrm{mg}$ ) was pressed into a $18 \mathrm{~mm}$ selfsupporting disk, adjusted in a sample holder, and put into a double-sealed glass high vacuum reactor equipped with $\mathrm{CaF}_{2}$ windows. After calcination at $500^{\circ} \mathrm{C}$ under air for 2 to 4 hours, the silica disk was treated under high vacuum $\left(10^{-5}\right.$ torr $)$ at $500^{\circ} \mathrm{C}$ for 12 hours. The silica support thus obtained, referred to as $\mathrm{SiO}_{2-(500)}(35 \mathrm{mg}, 16 \mu \mathrm{mol} \equiv \mathrm{SiOH})$, was then exposed to a large excess of dry triethylamine using a classical break-seal technique at $40^{\circ} \mathrm{C}$ for 4 hours, followed by a desorption step in liquid nitrogen. An excess of methyltrichlorosilane was then added at room temperature for 3 hours using a classical breakseal technique, followed by a desorption step ( 4 hours, $150^{\circ} \mathrm{C}$, $10^{-5}$ torr) to afford the formation of $\mathrm{SiO}_{2-(500) /[\mathrm{SiCl}] \text {. }}$ 
2.5. Synthesis of Potassium $\beta_{2}$-Undecatungstosilicate $K_{8}\left[\beta_{2}\right.$ $\left.\mathrm{SiW}_{11} \mathrm{O}_{39}\right] \cdot \mathrm{xH}_{2} \mathrm{O}$. Potassium $\beta_{2}$-undecatungstosilicate was synthesized according to a previous published procedure [11] and was obtained as a white solid (yield: 45\%). Polarography $\left(1 \mathrm{~mol} \cdot \mathrm{L}^{-1}\right.$ sodium acetate- $1 \mathrm{~mol} \cdot \mathrm{L}^{-1}$ acetic acid buffer $)$ : two reversible two-electron waves, with half-wave potentials at -0.62 and $-0.76 \mathrm{~V}$ versus SCE. Elemental analyses: $\mathrm{Si}$ $0.91_{\mathrm{wt}} \%, \mathrm{~W} 60.78_{\mathrm{wt}} \%$. Molar ratio (theory): W/Si 10.20 (11). ${ }^{29} \mathrm{Si} \operatorname{NMR}(\delta \mathrm{ppm}):-83.9\left(\mathrm{~K}_{8}\left[\beta_{2} \underline{\mathrm{SiW}}_{11} \mathrm{O}_{39}\right] \cdot x \mathrm{H}_{2} \mathrm{O}\right)$.

2.6. Synthesis of Potassium $\gamma$-Decatungstosilicate $K_{8}[\gamma$ $\left.\mathrm{SiW}_{10} \mathrm{O}_{36}\right] \cdot x \mathrm{H}_{2} \mathrm{O}$. The potassium salt of the $\gamma$-decatungstosilicate was synthesized according to a previous published procedure as a white solid [11] (yield: 60\%). Polarography $\left(1 \mathrm{~mol} \cdot \mathrm{L}^{-1}\right.$ sodium acetate- $1 \mathrm{~mol} \cdot \mathrm{L}^{-1}$ acetic acid buffer $)$ : two reversible two-electron waves, with half-wave potentials at -0.74 and $-0.87 \mathrm{~V}$ versus SCE. Elemental analyses: Si $0.93_{\mathrm{wt}} \%$, W $58.54_{\mathrm{wt}} \%$. Molar ratio (theory): W/Si $9.62(10)$. Solid state MAS ${ }^{29} \mathrm{Si}$ NMR ( $\delta$ ppm): $-86.1\left(\mathrm{~K}_{8}\right.$ $\left.\left[\gamma-\mathrm{SiW}_{10} \mathrm{O}_{36}\right] \cdot x \mathrm{H}_{2} \mathrm{O}\right)$.

2.7. Acidic Cation Exchange of Potassium $\gamma$-Decatungstosilicate $\mathrm{K}_{8}\left[\gamma-\mathrm{Si}_{10} \mathrm{O}_{36}\right] \cdot \mathrm{xH}_{2} \mathrm{O}$. The acidic cation exchange of potassium $\gamma$-decatungstosilicate was performed on a strongly acidic cation exchanger with sulfonic groups based on styrene-DVB copolymer according to a previous published procedure [12]. A rapid titration of the $\mathrm{H}_{8}-[\gamma$ $\mathrm{SiW}_{10} \mathrm{O}_{36}$ ] aqueous solution by a potassium hydroxide solution $\left(0.315 \mathrm{~mol} \cdot \mathrm{L}^{-1}\right)$ showed seven strong acidities and a weak one (the two inflexion points are, respectively, observed at 12.7 and $14.5 \mathrm{~mL}$ ).

2.8. Synthesis of $X_{4}\left[\left(\gamma-S_{i} W_{10} O_{36}\right)(\mathrm{MeSiOH})_{2}\right]$ (1a if $X=$ $n-B u_{4} N, 2 a$ if $\left.X=C s\right)$. The synthesis of the bis(tert-butylsilyl)decatungstosilicate anion $\left[\left(\gamma-\mathrm{SiW}_{10} \mathrm{O}_{36}\right)(\mathrm{MeSiOH})_{2}\right]^{4-}$ was inspired from the published procedure for its phosphorus-based homologue [8]. Both caesium and tetrabutylammonium salts of this anion were carried out and obtained as a light yellow powder. ${ }^{1} \mathrm{H}$ NMR $\left(\mathrm{CD}_{3} \mathrm{CN}\right.$, $\delta \mathrm{ppm}): 0.10\left(\mathrm{Cs}_{4}\left[\left(\gamma-\mathrm{SiW}_{10}\right)(\underline{\mathrm{MeSiOH}})_{2}\right]\right) ; 5.51\left(\mathrm{Cs}_{4}[(\gamma-\right.$ $\left.\left.\left.\mathrm{SiW}_{10}\right)(\mathrm{MeSiOH})_{2}\right]\right) .{ }^{13} \mathrm{C}\left\{{ }^{1} \mathrm{H}\right\}$ NMR $\left(\mathrm{CD}_{3} \mathrm{CN}, \delta\right.$ ppm): 22.1 $\left(\mathrm{Cs}_{4}\left[\left(\gamma-\mathrm{SiW}_{10}\right)(\underline{\mathrm{MeSiOH}})_{2}\right]\right) .{ }^{29} \mathrm{Si} \mathrm{NMR}(\delta \mathrm{ppm}):-65.6$ $\left(\mathrm{Cs}_{4}\left[\left(\gamma-\underline{\mathrm{SiW}}_{10}\right)(\overline{\mathrm{Me}} \underline{\mathrm{SiOH}})_{2}\right]\right)$.

2.9. Synthesis of $X_{4}\left[\left(\gamma-S i W_{10} O_{36}\right)(M e S i O D)_{2}\right]$ (1 $b$ if $X=n$ $\mathrm{Bu}_{4} \mathrm{~N}, \mathbf{2} \boldsymbol{b}$ if $\mathrm{X}=\mathrm{Cs}$ ). The bis (tert-butylsilyl) decatungstosilicate anion was washed with small amounts of deuterated water $(3 \times 3 \mathrm{~mL})$. The obtained solids with caesium and tetrabutylammonium salts were then dried overnight under vacuum to afford deuterated solids as light yellow powders. Elemental analyses: Si $2.97_{\mathrm{wt}} \%, \mathrm{~W} 46.07_{\mathrm{wt}} \%$. Molar ratio: W/Si 2.37 (3.33). ${ }^{1} \mathrm{H}$ NMR ( $\left.\mathrm{CD}_{3} \mathrm{CN}, \delta \mathrm{ppm}\right): 0.10\left(\mathrm{Cs}_{4}[(\gamma-\right.$ $\left.\left.\left.\mathrm{SiW}_{10}\right)(\underline{\mathrm{MeSiOH}})_{2}\right]\right) ; 5.51\left(\mathrm{Cs}_{4}\left[\left(\gamma-\mathrm{SiW}_{10}\right)(\mathrm{MeSiOH})_{2}\right]\right.$, weak signal).

2.10. Preparation of $\left(n-\mathrm{Bu}_{4} \mathrm{~N}\right)_{4}\left[\left(\gamma-\mathrm{Si}_{10} \mathrm{O}_{36}\right)(\mathrm{MeSiO})_{2}\right] / \mathrm{SBA}$ $15_{(500) /[S i C l]}$ by Impregnation of (1b) on SBA-15 ${ }_{(500)}$ Passivated by Surface Geminal Chlorosilanes. A mixture of ( $n$ $\left.\mathrm{Bu}_{4} \mathrm{~N}\right)_{4}\left[\left(\gamma-\mathrm{SiW}_{10} \mathrm{O}_{36}\right)(\mathrm{MeSiOD})_{2}\right], \mathbf{1 b},(1.33 \mathrm{~g}, 0.38 \mathrm{mmol})$ and $\mathrm{SBA}-15_{(500) /[\mathrm{SiCl}]}(1 \mathrm{~g}, 0.77 \mathrm{mmol} \mathrm{SiCl})$ in acetonitrile $(10 \mathrm{~mL})$ was stirred at $25^{\circ} \mathrm{C}$ for two days. After filtration, the solid was washed three times with acetonitrile and all volatile compounds were condensed into a reactor of known volume so as to analyse the gaseous phase evolved during the grafting. The resulting light yellow powder was dried 1 hour at room temperature under high vacuum $\left(10^{-5}\right.$ torr $)$ and stored under argon.

\section{Results and Discussion}

3.1. Partially Dehydroxylated and Chlorinated Silica Support. The reaction of chlorosilanes with the surface of silica has been widely studied owing to their applications in many areas of the materials thus obtained. The preparation of samples is usually made without any standard air-free methodology. The derivatization provides therefore the formation by self-assembly of a monolayer of silane deposited on silica [13] and/or a mixture of surface species due to the high silanol density on the silica surface. In addition, hydroxyl functionalities can be present as three types of silanols: isolated, germinal, or vicinal. Several articles reported that a dichloromethylsilane or trichloromethylsilane molecule can react with one or two surface hydroxyl groups if they are sufficiently close to each other (Scheme 1) [14-16]. Note that the reaction of trichloroalkylsilane with three surface hydroxyl groups is held to be unlikely due to steric hindrances.

It seems therefore quite difficult to prepare a starting support oxide containing only geminal or isolated chlorosilane groups as anchors unless introducing the tools of surface organometallic chemistry (SOMC). The basic principle of this field consists in grafting an organometallic compound on a partially dehydroxylated silica on which anchors, made of surface silanols in the present case, are homogeneously distributed and isolated from each other. This is achieved by a thermal treatment of the support under high vacuum. The reactivity of this partially dehydroxylated support was studied in presence of $\mathrm{CH}_{3} \mathrm{SiCl}_{3}$ so as to get the desired functionalization.

The oxide supports used in this study were a mesoporous silica SBA-15 $\left(1000 \mathrm{~m}^{2} \cdot \mathrm{g}^{-1}\right)$, characterized by a 2D-hexagonal structure and an average pore diameter of $6.5 \mathrm{~nm}$. In both cases the isolated, germinal, or vicinal hydroxyl groups are nonacidic. Up to $700^{\circ} \mathrm{C}$, partial dehydroxylation under vacuum does not change the specific surface area of silica while the relative concentration of the different silanols depends on the treatment temperature. The dehydroxylation process takes place first by desorption of physisorbed water, followed by condensation of vicinal $\mathrm{OH}$ groups above $150-$ $200^{\circ} \mathrm{C}$ (Scheme 2). A partial dehydroxylation leads to the formation of isolated hydroxyl groups. At $200-300^{\circ} \mathrm{C}$, this treatment provides very hydroxyl rich silica surfaces, which are mainly composed of vicinal $\mathrm{OH}$, while a treatment at $500^{\circ} \mathrm{C}$ (oxide support referred to as SBA-15(500) ) allows the statistical distribution of mainly isolated $\mathrm{OH}$ groups at an average distance of $c a .8 \AA$, which corresponds to a $\mathrm{OH}$ density of $1.4 \mathrm{OH} \cdot \mathrm{nm}^{-2}$, that is, $2.340 \mathrm{mmol} \mathrm{OH} \cdot \mathrm{g}^{-1}$ for SBA-15 $(500)$. 


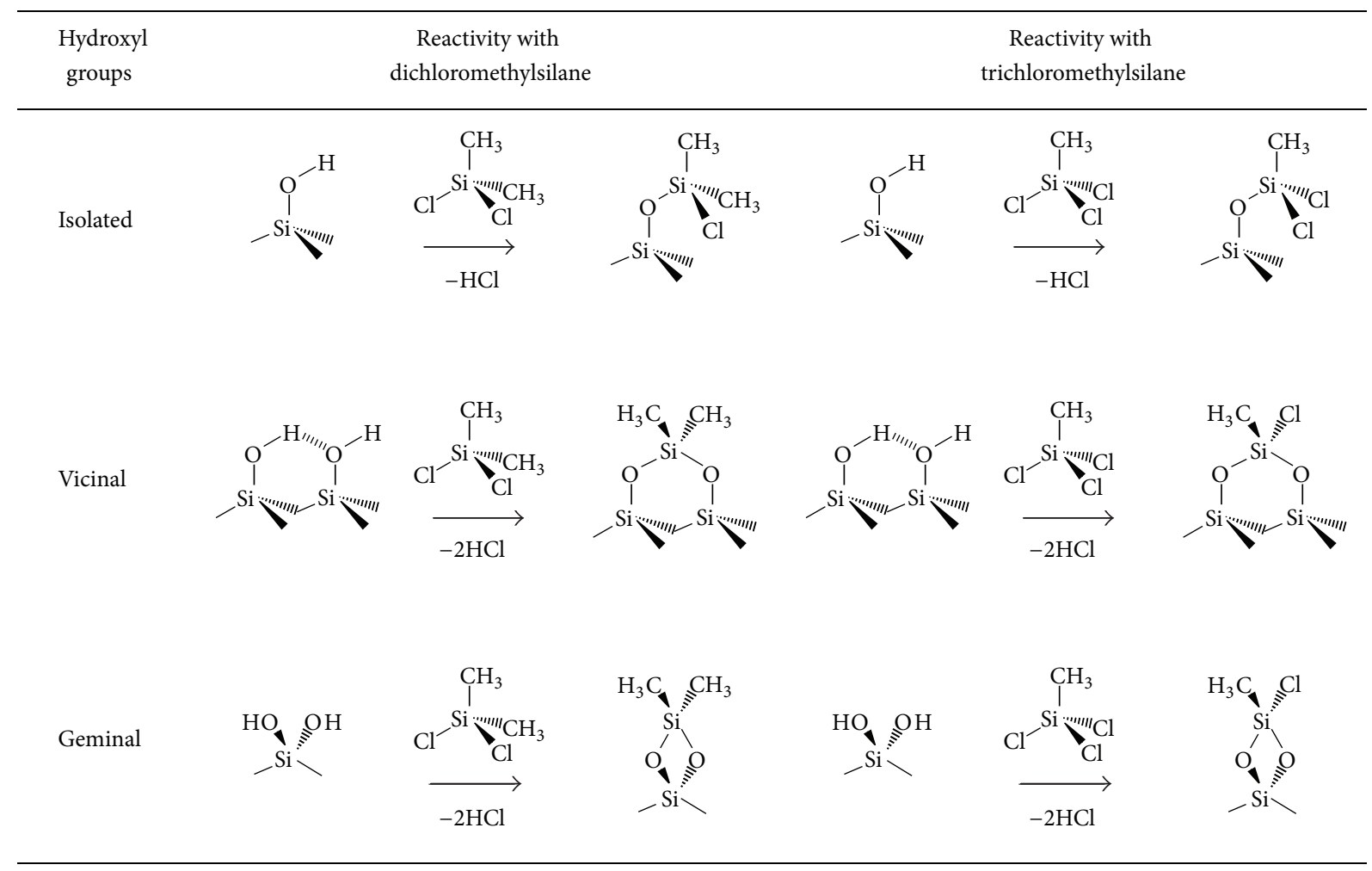

Scheme 1: Reactivity of di- and trichloromethylsilane with surface silanol groups.

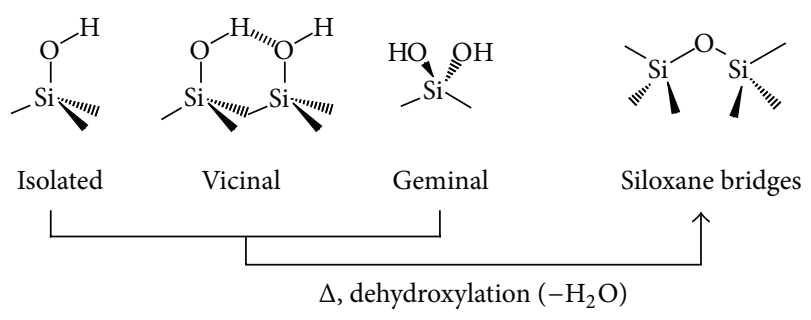

Scheme 2: Partial dehydroxylation of the silica surface.

The reaction of trichloromethylsilane with the silica surface was performed upon the work reported by Hair and Tripp in which the derivatization reaction was monitored by infrared spectroscopy using the "thin-film" technique [16]. Their experiments have shown that the silanisation of silica with an alkyltrichlorosilane does not proceed at temperatures below $350^{\circ} \mathrm{C}$. At room temperature, the reactant is only physically adsorbed on silica resulting in hydrogen bonds with the surface hydroxyl groups but no reaction occurs. Nevertheless, the reaction can proceed at room temperature by the use of a two-step mechanism as depicted in Scheme 3 [17].

In the first step a strong lone pair base such as triethylamine is adsorbed on silica introducing $\mathrm{H}$-bonds with the hydroxyl groups. This induces a strongly nucleophilic oxygen at the surface silanol which is then able to interact with the incoming chlorosilane to form a geminal chlorosilane at the silica surface, the base being released as a chloride salt
$\mathrm{HNEt}_{3}{ }^{+} \mathrm{Cl}^{-}$. This reactivity was firstly monitored in situ by infrared spectroscopy with a pellet of silica partially dehydroxylated at $500^{\circ} \mathrm{C}$ using the classical break-seal technique and secondly applied to the preparations of partially dehydroxylated and chlorinated silica supports $\mathrm{SiO}_{2-(500) /[\mathrm{SiCl}]}$ and SBA-15 $(500) /[\mathrm{SiCl}]$ to get few grams.

Upon exposure to triethylamine, there is a complete disappearance of the isolated silanol groups $\left(\nu_{(\mathrm{OH})}\right.$ at $\left.3744 \mathrm{~cm}^{-1}\right)$ and the concomitant apparition of bands at $2977\left(\nu_{\mathrm{as}(\mathrm{CH} 3)}\right)$, $2944\left(\nu_{\mathrm{s}(\mathrm{CH} 3)}\right), 1475-1445\left(\delta_{\mathrm{as}(\mathrm{CH} 3)}\right)$, and $1380-1395 \mathrm{~cm}^{-1}$ $\left(\delta_{\mathrm{s}(\mathrm{CH} 3)}\right)$ characteristic of the ethyl groups. Moreover, broad adsorptions in the range $2700-2250 \mathrm{~cm}^{-1}$ are observed and assigned to a tertiary amine salt. This result is therefore consistent with the formation of a surface species in which the isolated silanols strongly interact with the tertiary amine according to $\equiv \mathrm{SiO}^{\delta^{-}} \cdots \mathrm{H} \cdots \mathrm{N}^{\delta+}(\mathrm{Et})_{3}$. After exposure to methyltrichlorosilane and a desorption step, the spectrum displays new bands at $2984\left(\nu_{\text {as }(\mathrm{CH} 3)}\right), 1408$ $\left(\delta_{\mathrm{as}(\mathrm{CH} 3)}\right)$, and $1374 \mathrm{~cm}^{-1}\left(\delta_{\mathrm{s}(\mathrm{CH} 3)}\right)$ characteristic of the methyl group. The disappearance of all isolated silanol groups $\left(\nu_{(\mathrm{OH})}\right.$ at $3744 \mathrm{~cm}^{-1}$ ) indicates a complete derivatization of the silica surface. As expected, the residual hydrogen-bonded silanols at $3673 \mathrm{~cm}^{-1}\left(\nu_{(\mathrm{OH})}\right)$ are not affected by the treatment with $\mathrm{Et}_{3} \mathrm{~N}$ and the subsequent reactivity of $\mathrm{CH}_{3} \mathrm{SiCl}_{3}$. The subtraction of the spectra resulting from the derivatization of the pellet and the partially dehydroxylated oxide support shows clearly the consumption of the isolated surface silanols and the appearance of methyl groups. 


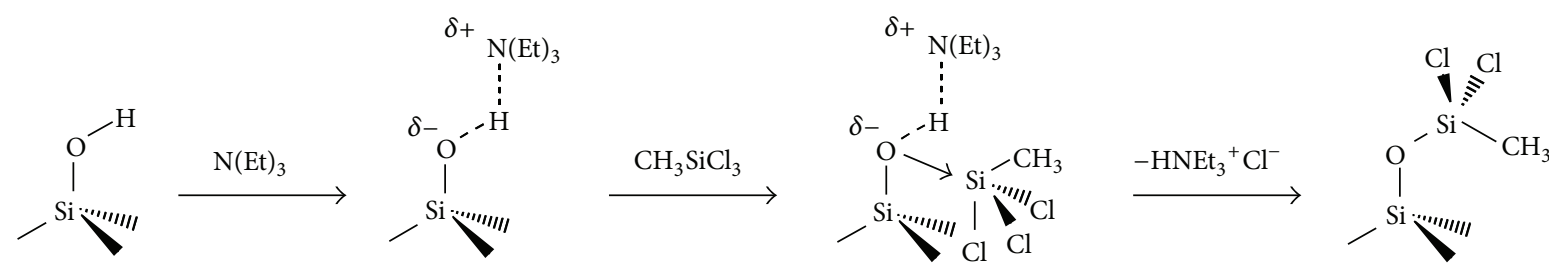

Scheme 3: Derivatization of silica surface with trimethylchlorosilane: nucleophilic mechanism with preadsorbed triethylamine.

TABLE 1: Specific areas, pore size, and volume distributions of the mesoporous silica samples.

\begin{tabular}{lcccc}
\hline Sample & $\begin{array}{c}\text { BET surface } \\
\text { area } \\
\left( \pm 30 \mathrm{~m}^{2} \cdot \mathrm{g}^{-1}\right)\end{array}$ & $\begin{array}{c}\text { Pore } \\
\text { diameter } \\
(\mathrm{nm})\end{array}$ & $\begin{array}{c}\text { Pore } \\
\text { volume } \\
\left(\mathrm{cm}^{3} \cdot \mathrm{g}^{-1}\right)\end{array}$ & $\mathrm{C}$ \\
\hline $\mathrm{SBA}^{-15}{ }_{(500)}$ & 875 & 6.5 & 0.99 & 716.9 \\
$\mathrm{SBA}^{-15}(500) /[\mathrm{SiCl}]$ & 540 & 6.0 & 0.73 & 71.9 \\
\hline
\end{tabular}

Owing to the strong absorption of silica below $1250 \mathrm{~cm}^{-1}$ and the cutoff of the $\mathrm{ZnSe}$ windows near $800 \mathrm{~cm}^{-1}$, it was not possible to observe the infrared bands characteristic of the Si$\mathrm{Cl}$ bond preventing to demonstrate directly the formation of a surface chlorosilane. However, an indirect proof was obtained by exposure of the pellet to a vapour pressure of water. A release of hydrochloric acid was observed due to the cleavage of $\mathrm{Si}-\mathrm{Cl}$ bonds by water, confirming their presence on the solid.

The preparation of the partially dehydroxylated and chlorinated silica support, SBA-15 $5_{(500) /[\mathrm{SiCl}]}$, was performed following the same scheme. The partially dehydroxylated silica sample was stirred with a triethylamine solution in pentane $\left(3 \mathrm{~h} ; 40^{\circ} \mathrm{C}\right)$, filtered and then stirred again with a methyltrichlorosilane solution in pentane $\left(3 \mathrm{~h} ; 40^{\circ} \mathrm{C}\right)$. The resulting powder was washed with pentane and dried. The formation of the chloride salt required a careful drying step of the solid $\left(24 \mathrm{~h} ; 150^{\circ} \mathrm{C} ; 10^{-5}\right.$ torr $)$.

Table 1 gives the textural parameters deduced from nitrogen adsorption isotherms on SBA $15_{(500)}$ and SBA- $15_{(500) /[\mathrm{SiCl}]}$ obtained after modification by $\mathrm{MeSiCl}_{3}$. The pore size distribution is in both cases narrow and centered at 6.5 and $6.0 \mathrm{~nm}$ before and after the surface derivatization, respectively, while the BET surface area and the pore volume have decreased. This decrease is rather similar to what can be expected when covering the surface with $-\mathrm{MeSiCl}_{2}$ groups, the size of these species being ca. $0.2 \mathrm{~nm}$.

The ${ }^{29} \mathrm{Si}$ CP-MAS NMR spectrum of SBA-15 ${ }_{(500) /[\mathrm{SiCl}]}$ depicted in Figure 1 displays three main resonances at $-14,-38$, and $-108 \mathrm{ppm}$. The resonance at $-108 \mathrm{ppm}$ corresponds to the $\mathrm{Si}(\equiv \mathrm{OSi})_{4}$ groups of silica while the two other peaks can be ascribed to alkylchlorosilane moieties grafted at the silica surface showing that the reaction leads to two surface species contrary to Scheme 1 . The resonance at $-14 \mathrm{ppm}$ can be assigned, according to the literature data, to the silicon atom of a methyldichlorosilane moiety grafted onto hydroxyl groups $\left[(\equiv \mathrm{SiO}) \underline{\mathrm{SiMeCl}}{ }_{2}\right]$. The second signal observed at $-38 \mathrm{ppm}$ can be ascribed to the silicon atom of a methylchlorosilane species digrafted at the silica surface $\left[(\equiv \mathrm{SiO})_{2} \underline{\mathrm{SiMeCl}}\right]$. Even if the sequence used in ${ }^{29} \mathrm{Si} \mathrm{NMR}$ was not quantitative (due to cross-polarization) but as the contact time of the two surface species is probably quite similar (they depict the same $\mathrm{H}_{3} \mathrm{C}-\mathrm{Si}$ chain), a rough estimate of their proportions gives ca. $1 / 3$ of $\left[(\equiv \mathrm{SiO}) \underline{\mathrm{SiMeCl}}_{2}\right]$ and $2 / 3$ of $\left[(\equiv \mathrm{SiO})_{2}\right.$ SiMeCl] .

In addition, elemental analyses of SBA- $15_{(500) /[\mathrm{SiCl}]}$ show that the sample contains $0.8 \pm 0.1 \mathrm{wt} . \% \mathrm{C}$ and $2.7 \pm 0.2 \mathrm{wt}$.\% $\mathrm{Cl}$. The amount of chlorine is lower than expected for a dichloro-species, the mean $\mathrm{Cl} / \mathrm{C}$ ratio being ca. 1.3 (in agreement with the above NMR results).

The ${ }^{1} \mathrm{H}$ MAS NMR spectrum of the solid displays two resonances at 0.2 and $-0.3 \mathrm{ppm}$ which can be assigned to the methyl group of chlorosilane moieties. In agreement with the above conclusion, the presence of two peaks near $0 \mathrm{ppm}$ indicates that there are two chlorosilane species grafted at the surface. No resonance corresponding to isolated surface silanols is observed at $1.8 \mathrm{ppm}$. This reveals that (i) the reactivity of the methyltrichlorosilane is complete onto partially dehydroxylated silica sample in agreement with infrared data and (ii) no cleavage of the $\mathrm{Si}-\mathrm{Cl}$ bond occurs during the reaction. Moreover, there is no resonance ascribable to the ammonium salt. The preparation of chlorinated silica appeared therefore to proceed through a clean reaction even if a mixture of species was obtained.

Similarly, the solid state ${ }^{13} \mathrm{C}$ CP-MAS NMR of SBA$15_{(500) /[\mathrm{SiCl}]}$ shows two resonances at respectively 2.7 and $-1.9 \mathrm{ppm}$ assigned to the methyl group of $\left[(\equiv \mathrm{SiO}) \mathrm{SiCH}_{3} \mathrm{Cl}_{2}\right]$ and $\left[(\equiv \mathrm{SiO})_{2} \mathrm{SiCH}_{3} \mathrm{Cl}\right]$ respectively.

In conclusion, the results are consistent with the formation of a mixture of alkylchlorosilane moities which are either mono- or digrafted at the surface of partially dehydroxylated silica. Considering the whole NMR and analytical data, a mean estimate of both species gives $c a$. one monografted species for two digrafted species.

The formation of a digrafted chlorosilane species even onto partially dehydroxylated silica can be explained by the distribution of surface silanols discussed in a recent published article [7]. It has indeed been shown by double and triplequantum proton spectroscopy that $\mathrm{SiO}_{2-(500)}$ and $\mathrm{SiO}_{2-(700)}$ samples display autocorrelation peaks revealing that the dehydroxylation process led to a silanol distribution which is not completely statistical. This means that even at high temperature, part of surface silanols is in a close environment which could enable, through silica derivatization, the formation of a digrafted species.

3.2. Synthesis of $\mathrm{Cs}_{4}\left[\left(\gamma-\mathrm{SiW}_{10} \mathrm{O}_{36}\right)(\mathrm{MeSiOH})_{2}\right]$. The synthesis of the bis(methylsilyl)decatungstosilicate organosilyl 


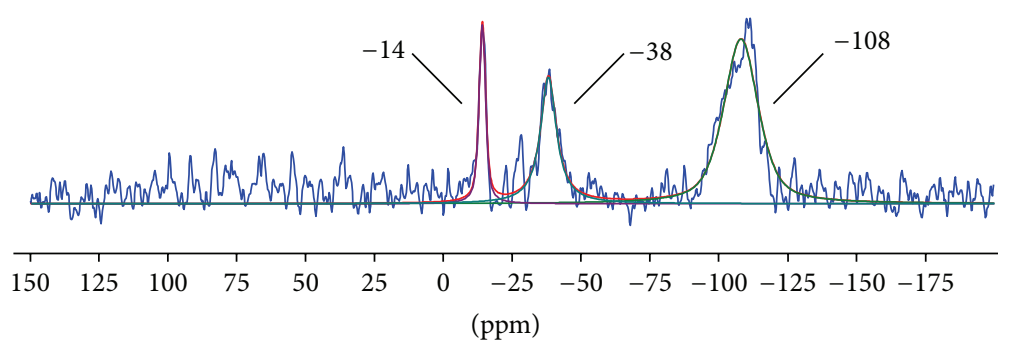

Figure 1: ${ }^{29} \mathrm{Si} \mathrm{CP-MAS} \mathrm{NMR} \mathrm{spectrum} \mathrm{of} \mathrm{SBA-} 15_{(500) /[\mathrm{SiCl}]}$ recorded at $5 \mathrm{KHz}$.

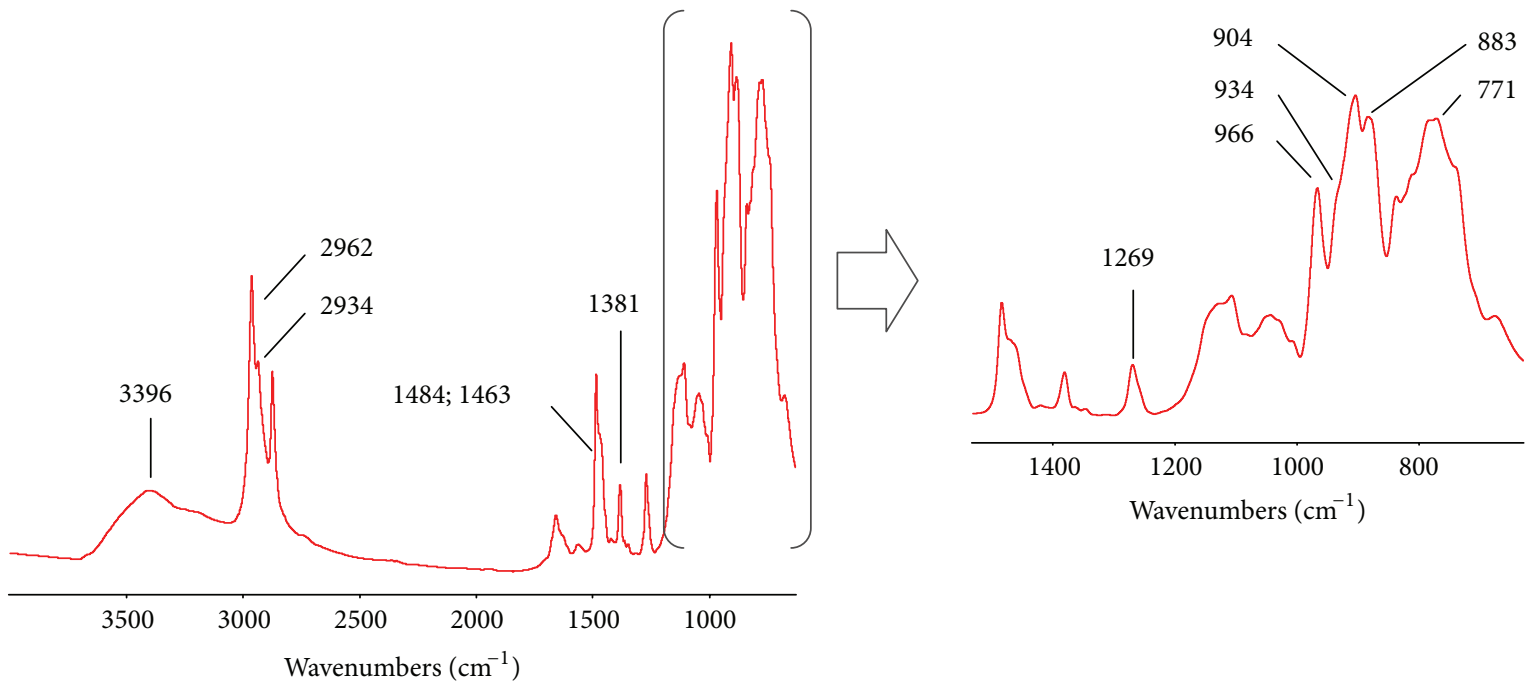

FIGURE 2: IR spectrum of $\left[n-\mathrm{Bu}_{4} \mathrm{~N}\right]_{4}\left[\left(\gamma-\mathrm{SiW}_{10} \mathrm{O}_{36}\right)(\mathrm{MeSiOH})_{2}\right]$ in $\mathrm{KBr}$.

derivative based on the $\gamma$-SiW $\mathrm{Si}_{10}$ Keggin structure was developed upon the work of Mazeaud et al. who reported the synthesis of the bis( $t$-butylsilyl)decatungstophosphate anion [8]. The X-ray analysis revealed an open structure with two unequivalent $t$ - $\mathrm{BuSiOH}$ groups attached to the polyoxometalate through two $\mathrm{W}-\mathrm{O}-\mathrm{Si}$ bridges. According to this published synthesis, a similar approach was developed to prepare the desired bis (methylsilyl) decatungstosilicate [ $\gamma$ $\left.\left.\mathrm{SiW}_{10} \mathrm{O}_{36}\right)(\mathrm{MeSiOH})_{2}\right]^{4-}$ starting from $\gamma$-decatungstosilicate prepared according to previously published methods [11]. The hybrid anion was first yielded with caesium chloride so as to achieve its complete characterization by liquid and solid-state NMR.

The ${ }^{1} \mathrm{H}$ liquid NMR of the modified $\gamma$-SiW ${ }_{10}$ Keggin structure displays two peaks at 0.10 and $5.51 \mathrm{ppm}$ ascribed, respectively, to a methyl group and a silanol group. These chemical shifts are in good agreement with the data reported for the phosphorus compound. Moreover, the ratio $\mathrm{SiOH} / \mathrm{CH}_{3}$ is equal to 1.1. Furthermore an H/D exchange was performed so as to corroborate the presence of silanol groups on the polyoxotungstate structure. In order to achieve it, the light yellow powder of $\mathrm{Cs}_{4}\left[\left(\gamma-\mathrm{SiW}_{10} \mathrm{O}_{36}\right)(\mathrm{MeSiOH})_{2}\right]$ was dried under vacuum, washed three times with small amounts of deuterated water, and then dried again under vacuum. The ${ }^{1} \mathrm{H}$ NMR spectrum of the resulting solid was recorded in $\mathrm{CD}_{3} \mathrm{CN}$ and showed a drastic decrease of the signal at $5.51 \mathrm{ppm}$, in agreement with the proposed attribution.
The ${ }^{13} \mathrm{C}$ liquid NMR spectrum displays only one signal at $22.1 \mathrm{ppm}$. This resonance is consistent with a carbon atom linked to a silyl moiety $\mathrm{CH}_{3}-\mathrm{Si}$. In the case of the anchored $t$-butyl fragment, the resonance was found at $18.9 \mathrm{ppm}\left(\left(\mathrm{CH}_{3}\right)_{3} \mathrm{C}-\mathrm{Si}\right)$. The solid state ${ }^{29} \mathrm{Si}$ CP-MAS NMR of the $\mathrm{Cs}_{4}\left[\left(\gamma-\mathrm{SiW}_{10} \mathrm{O}_{36}\right)(\mathrm{MeSiOH})_{2}\right]$ shows a resonance at $-65.6 \mathrm{ppm}$ ascribed to the silicon atoms of the $\mathrm{MeSiOH}$ groups. The central silicon atom of the Keggin structure was not detected due to the use of a $\mathrm{CP}$ sequence.

The infrared spectrum of $\left[n-\mathrm{Bu}_{4} \mathrm{~N}\right]_{4}\left[\left(\gamma-\mathrm{SiW}_{10} \mathrm{O}_{36}\right)\right.$ $\left.(\mathrm{MeSiOH})_{2}\right]$ is shown on Figure 2. The solid displays bands characteristic of alkyl groups at $2962\left(v_{\mathrm{as}(\mathrm{CH} 3)}\right), 2934\left(v_{\mathrm{s}(\mathrm{CH} 3)}\right)$, 1484 and $1463\left(\delta_{\mathrm{as}(\mathrm{CH} 3)}\right)$, and $1381 \mathrm{~cm}^{-1}\left(\delta_{\mathrm{s}(\mathrm{CH} 3)}\right)$. The broad signal at $3396 \mathrm{~cm}^{-1}$ cor-responds to the $\nu_{(\mathrm{OH})}$ stretching vibration. The structure of the heteropolyoxotungstate examined in the range $1500-700 \mathrm{~cm}^{-1}$ is very similar to the starting material $\mathrm{K}_{8}-\left[\gamma-\mathrm{SiW}_{10} \mathrm{O}_{36}\right]$ except that a shift to higher wavenumbers is observed. This result is consistent with the infrared data reported on the bis(t-butylsilyl) decatungstophosphate anion and indicates the stabilization of the polyoxometalate framework. The bands observed at 966 and $904 \mathrm{~cm}^{-1}\left(\nu_{(\mathrm{W}=\mathrm{Od})}\right), 934 \mathrm{~cm}^{-1}\left(\nu_{(\mathrm{Si}-\mathrm{O})}\right), 883$, and $771 \mathrm{~cm}^{-1}\left(\nu_{(\mathrm{W}-\mathrm{O}-\mathrm{W})}\right)$ were assigned according to literature data. Moreover the band observed at $1269 \mathrm{~cm}^{-1}$ corresponds to a $\nu_{\text {(Si-alkyl) }}$ vibration which is therefore consistent with an alkylsilyl group anchored on the polyoxometalate structure. 


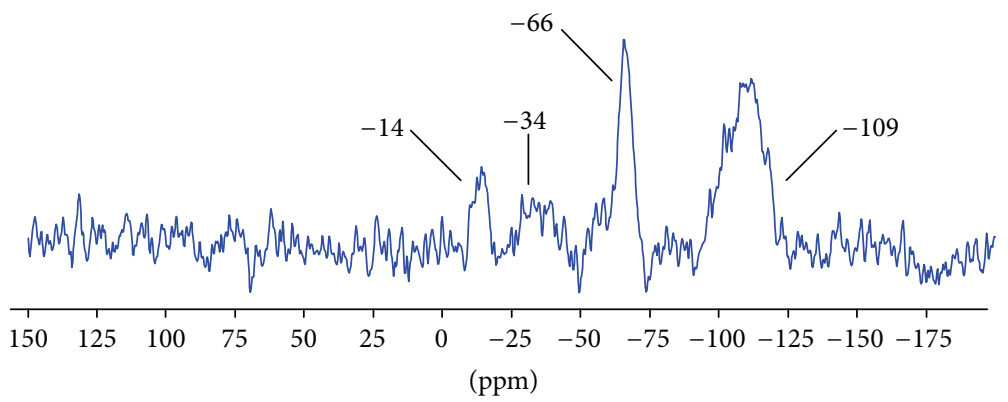

Figure $3:{ }^{29} \mathrm{Si} \mathrm{CP-MAS} \mathrm{NMR} \mathrm{spectrum} \mathrm{of}\left[\left(\gamma-\mathrm{SiW}_{10} \mathrm{O}_{36}\right)(t-\mathrm{BuSiO})_{2}\right] / \mathrm{SiO}_{2-(500) /[\mathrm{SiCl}]}$.

TABLE 2: Relative intensities of chlorosilane moitsies before and after reaction with the polyoxometalate based on ${ }^{29} \mathrm{Si}$ NMR data.

\begin{tabular}{lccccc}
\hline${ }^{29} \mathrm{Si} \mathrm{chemical} \mathrm{shift}(\mathrm{ppm})$ & Proportions (\%) & \multicolumn{3}{c}{ Relative intensities } \\
& $\delta_{1}(-14)$ & $\delta_{2}(-34)$ & $\delta_{3}(-109)$ & $\delta_{1} / \delta_{3}$ & 0.20 \\
$\mathrm{SiO}_{2-(500) /[\mathrm{SiCl}]}$ & 13 & 26 & 61 & $\delta_{2} / \delta_{3}$ \\
{$\left[\gamma-\mathrm{SiW}_{10}\right] / \mathrm{SiO}_{2-(500) /[\mathrm{SiCl}]}$} & 14 & 16.0 & 70 & 0.20 & 0.23 \\
\hline
\end{tabular}

Elemental analyses (W 46.1 $\%$, Si 3.0 ${ }_{\mathrm{wt}} \%, \mathrm{~W} / \mathrm{Si}$ (theory) 2.37 (3.33)) as well as NMR and IR data are therefore in good agreement with the formation of a heteropolyoxometalate with a methylsilyl group anchored to its backbone.

\subsection{Reaction of the Polyoxometalate with Chlorinated} Silica. The grafting reaction of $\left[n-\mathrm{Bu}_{4} \mathrm{~N}\right]_{4}\left[\left(\gamma-\mathrm{SiW}_{10} \mathrm{O}_{36}\right)\right.$ $\left.(\mathrm{MeSiOD})_{2}\right]$ (1b) on SBA-15 ${ }_{(500) /[\mathrm{SiCl}]}$ was achieved using an impregnation technique. A mixture of the polyoxometalate and chlorinated silica in equimolar amounts was stirred at $25^{\circ} \mathrm{C}$ for two days in acetonitrile. The excess of hybrid anion was eliminated by washings with the same solvent (filtration/distillation cycles). Gas phase analysis showed the presence of hydrochloric acid indicating that the reaction took place. Nevertheless, the quantification was not possible as only a part of the volatile compounds were effectively present in the gaseous phase. The resulting light yellow polyoxometalate species, $\mathbf{1 b} / \mathrm{SBA}-15_{(500) /[\mathrm{SiCl}]}$ obtained after drying under high vacuum at $25^{\circ} \mathrm{C}$, contained $12.0 \mathrm{wt} . \%$ of tungsten ( $16.7 \mathrm{wt} \%$ of polyoxometalate). This value is $c a$. three times lower than what could be expected from the number of starting silanol groups or chlorinated species. Elemental analyses suggest consequently that the grafting reaction is not complete.

One possibility could be that steric effects prevent the reaction of the surface $\mathrm{Si}-\mathrm{Cl}$ groups with the polyoxometalate. In order to check if that hypothesis was true we performed modelling molecular studies with the more sterically hindered polyoxometalate $\left[\left(\gamma-\mathrm{SiW}_{10} \mathrm{O}_{36}\right)(t\right.$ $\left.\mathrm{BuSiOH})_{2}\right]^{4-}$. These molecular modelling studies showed that if one assumes a homogeneous repartition of $\mathrm{Si}-\mathrm{Cl}$ species on the surface, all surface sites could react, the coverage being lower than the amount of polyoxometalate which could be put on the surface as a monolayer. The fact that only a small part of the starting $\mathrm{Si}-\mathrm{Cl}$ species reacts is probably due to another reason.

The ${ }^{29} \mathrm{Si}$ MAS NMR spectrum of the obtained solid is depicted on Figure 3 and displays four resonances at
$-14,-34,-66$, and $-109 \mathrm{ppm}$. The broad resonance at $-109 \mathrm{ppm}$ corresponds as previously to the silica support. The resonance at -66 was assigned to the silicon atoms of the polyoxotungstate structure according to the NMR data of the starting material. The two signals at -14 and $-34 \mathrm{ppm}$ correspond to the chlorosilanes moities grafted onto silica (resp. $\left[(\equiv \mathrm{SiO}) \underline{\mathrm{SiMeCl}}{ }_{2}\right]$ and $\left.\left[(\equiv \mathrm{SiO})_{2} \underline{\mathrm{SiMeCl}}\right)\right]$, as shown above. The relative intensities of these two resonances can be compared with those of the starting derivatized oxide support and indicate that ca. $5 \%$ of $\left[(\equiv \mathrm{SiO}) \mathrm{SiMeCl}_{2}\right]$ and $45 \%$ of $\left[(\equiv \mathrm{SiO})_{2} \mathrm{SiMeCl}\right]$ were consumed (Table 2$)$. These data are consistent with the mean coverage of the oxide support found by elemental analysis.

The fact that the digrafted monochloro species reacts preferentially with the polyoxometalate is probably related to different locations of mono- and digrafted compounds on the surface. As SBA-15 (the spectra were obtained on this support) contains microporosity, one explanation could be that the monografted chloro species are located mainly in the micropores while the digrafted ones are mainly located in the mesopores. Due to its size the polyoxometalate cannot react in micropores and so only the reaction product with digrafted chloro-species should be observed. However we have no proof of such a location which remains an hypothesis.

\section{Conclusion}

In conclusion, we have reported a covalent grafting (postsynthesis) strategy to prepare silica-supported polyoxometalate which consists in controlling the formation of surface species. This approach based on the tools of Surface Organometallic Chemistry was performed using the bis(methylsilyl) decatungstosilicate hybrid POM with a partially dehydroxylated and chlorinated silica support also fully characterized. The support functionalization with $\mathrm{CH}_{3} \mathrm{SiCl}_{3}$ led to a mixture of two chlorinated surface species which were either monografted $\left(\left[(\equiv \mathrm{SiO}) \mathrm{SiMeCl}_{2}\right], 33 \%\right)$ or digrafted $\left.\left[(\equiv \mathrm{SiO})_{2} \mathrm{SiMeCl}\right], 66 \%\right)$ on silica. Then, the grafting reaction 
of the hybrid deuterated POM with this chlorinated silica was performed and led to the evolution of $\mathrm{DCl}$. Only the digrafted silane $\left[(\equiv \mathrm{SiO})_{2} \mathrm{SiMeCl}\right]$ reacted with the polyoxometalate leading to the formation of a covalently bonded polyoxometalate $(\equiv \mathrm{SiO})_{2} \mathrm{Si}(\mathrm{Me})-\mathrm{O}-\mathrm{Si}(\mathrm{Me})=(\mathrm{POM})$ species.

This novel approach to prepare well-defined silicasupported POMs constitutes a suitable grafting method to get stable and uniformly distributed POM units. Thus the results presented in this paper establish a milestone to generate a completely new class of POMs-based materials displaying the advantages of the two main strategies classically described in the literature.

\section{References}

[1] M. T. Pope, Heteropoly and Isopoly Oxometalates, Springer, Berlin, Germany, 1983.

[2] H. K. Yang, Y. X. Cheng, M. M. Su et al., "Polyoxometalatebiomolecule conjugates: a new approach to create hybrid drugs for cancer therapeutics," Bioorganic \& Medicinal Chemistry Letters, vol. 23, no. 5, pp. 1462-1466, 2013.

[3] D. Liu, Y. Lu, H. Q. Tan et al., "Polyoxometalate-based purely inorganic porous frameworks with selective adsorption and oxidative catalysis functionalities," Chemical Communications, vol. 49, no. 35, pp. 3673-3675, 2013.

[4] N. Joo, S. Renaudineau, G. Delapierre et al., "Organosilyl/germyl polyoxotungstate hybrids for covalent grafting onto silicon surfaces: towards molecular memories," Chemistry, vol. 16, no. 17, pp. 5043-5051, 2010.

[5] A. Proust, B. Matt, R. Villanneau, G. Guillemot, P. Gouzerh, and G. Izzet, "Functionalization and post-functionalization: a step towards polyoxometalate-based materials," Chemical Society Reviews, vol. 41, no. 22, pp. 7605-7622, 2012.

[6] V. Dufaud and F. Lefebvre, "Inorganic hybrid materials with encapsulated polyoxometalates," Materials, vol. 3, no. 1, pp. 682703, 2010 .

[7] E. Grinenval, X. Rozanska, A. Baudouin et al., "Controlled interactions between anhydrous keggin-type heteropolyacids and silica support: preparation and characterization of welldefined silica-supported polyoxometalate species," Journal of Physical Chemistry C, vol. 114, no. 44, pp. 19024-19034, 2010.

[8] A. Mazeaud, Y. Dromzee, and R. Thouvenot, "Organic-inorganic hybrids based on polyoxometalates. 6.1 Syntheses, structure, and reactivity of the Bis(tert-butylsilyl)decatungstophosphate $\left[\left(\gamma-\mathrm{PW}_{10} \mathrm{O}_{36}\right)(\mathrm{t}-\mathrm{BuSiOH})_{2}\right]^{3-}$," Inorganic Chemistry, vol. 39, no. 21, pp. 4735-4740, 2000.

[9] W. H. Knoth, "Derivatives of heteropolyanions. 1. Organic derivatives of W12SiO404-, W12PO403-, and MO12SiO404-," Journal of the American Chemical Society, vol. 101, no. 3, pp. 759760, 1979.

[10] D. D. Perrin and W. L. F. Armarego, Purification of Laboratory Chemicals, Pergamon Press, New York, NY, USA, 3rd edition, 1988.

[11] A. Tézé and G. Hervé, “ $\alpha$-, $\beta$-, and $\gamma$-dodecatungstosilicic acids: isomers and related lacunary compounds," Inorganic Syntheses, vol. 27, article 85, 1990.

[12] J. Canny, A. Tézé, R. Thouvenot, and G. Hervé, “Disubstituted tungstosilicates. 1. Synthesis, stability, and structure of the lacunary precursor polyanion of a tungstosilicate .gamma.SiW10O368-," Inorganic Chemistry, vol. 25, pp. 2114-2119, 1986.
[13] J. D. Le Grange, J. L. Markham, and C. R. Kurkjian, "Effects of surface hydration on the deposition of silane monolayers on silica," Langmuir, vol. 9, no. 7, pp. 1749-1753, 1993.

[14] C. G. Armistead, A. J. Tyler, F. H. Hambleton, S. A. Mitchell, and J. A. Hockey, "The surface hydroxylation of silica," Journal of Physical Chemistry, vol. 73, no. 11, pp. 3947-3953, 1969.

[15] M. L. Hair and W. Hertl, "Reactions of chlorosilanes with silica surfaces," Journal of Physical Chemistry, vol. 73, no. 7, pp. 23722378, 1969.

[16] M. L. Hair and C. P. Tripp, "Alkylchlorosilane reactions at the silica surface," Colloids and Surfaces A: Physicochemical and Engineering Aspects, vol. 105, no. 1, pp. 95-103, 1995.

[17] C. P. Tripp, M. L. Hair, and R. P. N. Veregin, Application: US 1992-996390, Xerox Corp., Norwalk, Conn, USA, 1994. 

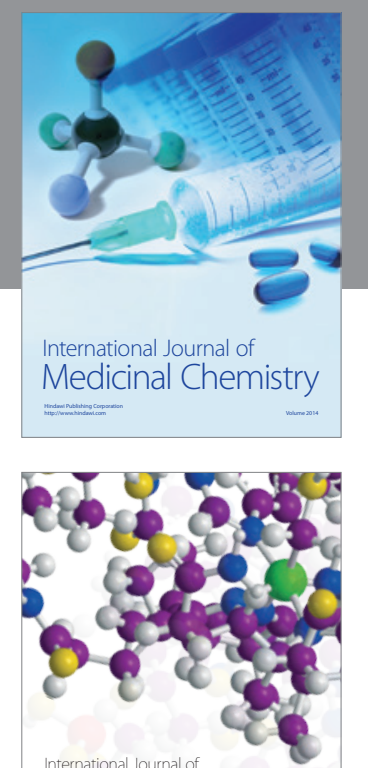

\section{Carbohydrate} Chemistry

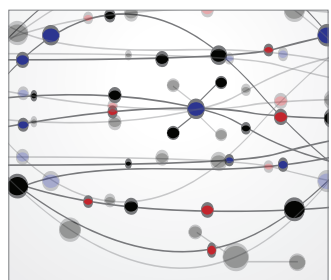

The Scientific World Journal
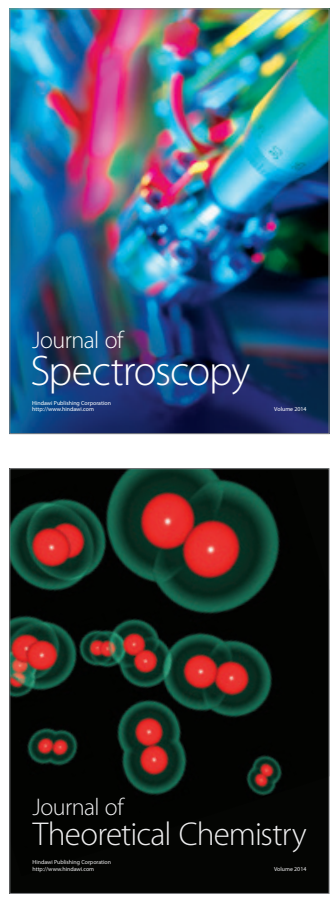
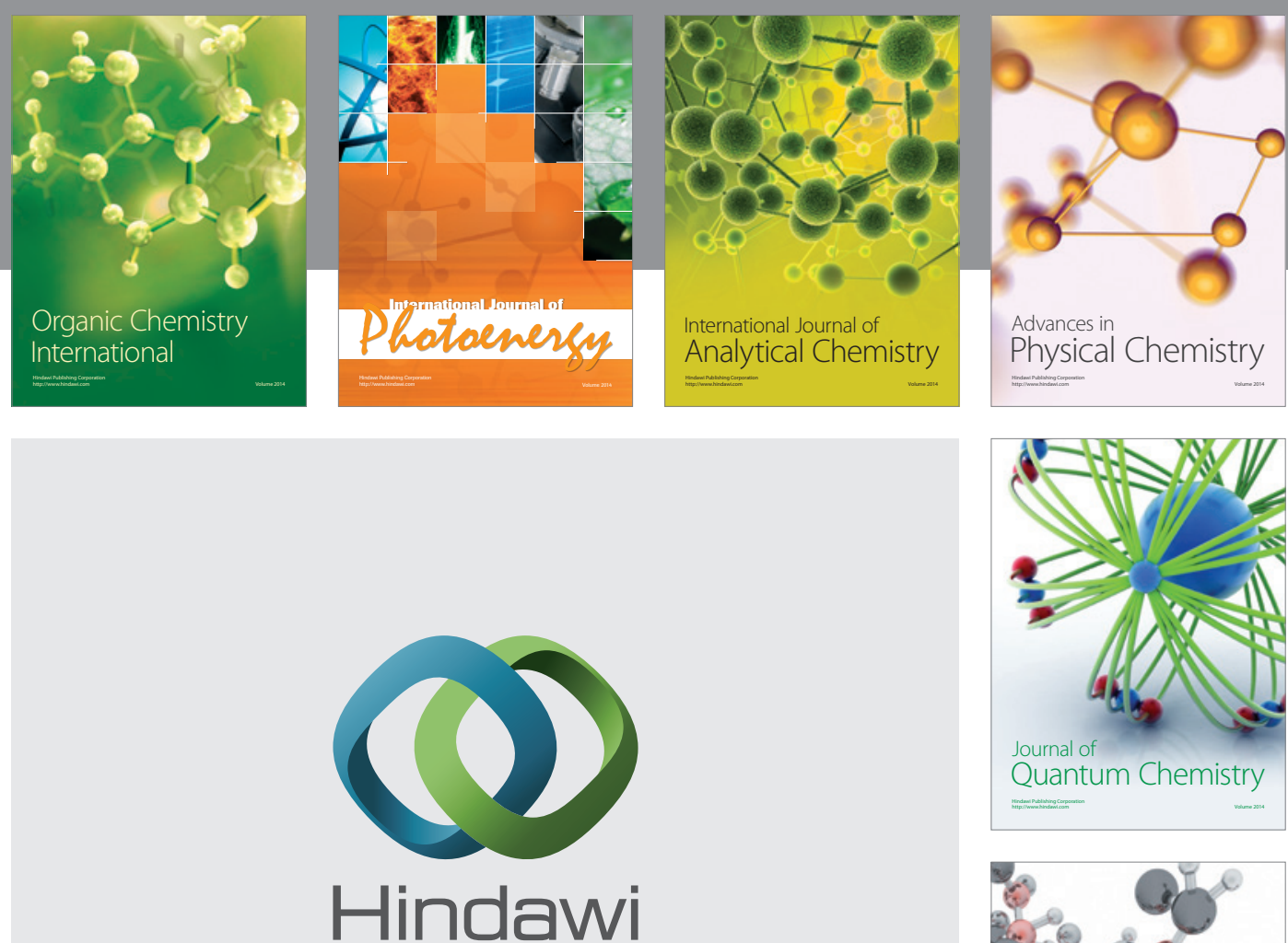

Submit your manuscripts at

http://www.hindawi.com

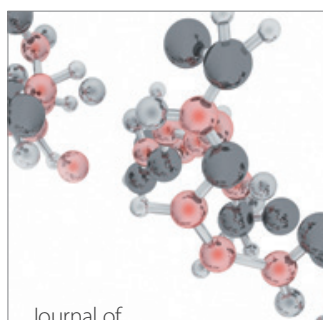

Analytical Methods

in Chemistry

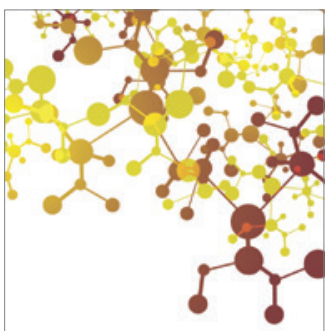

Journal of

Applied Chemistry

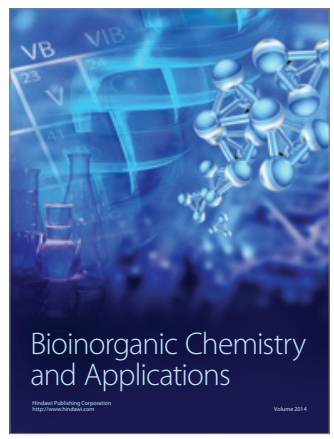

Inorganic Chemistry
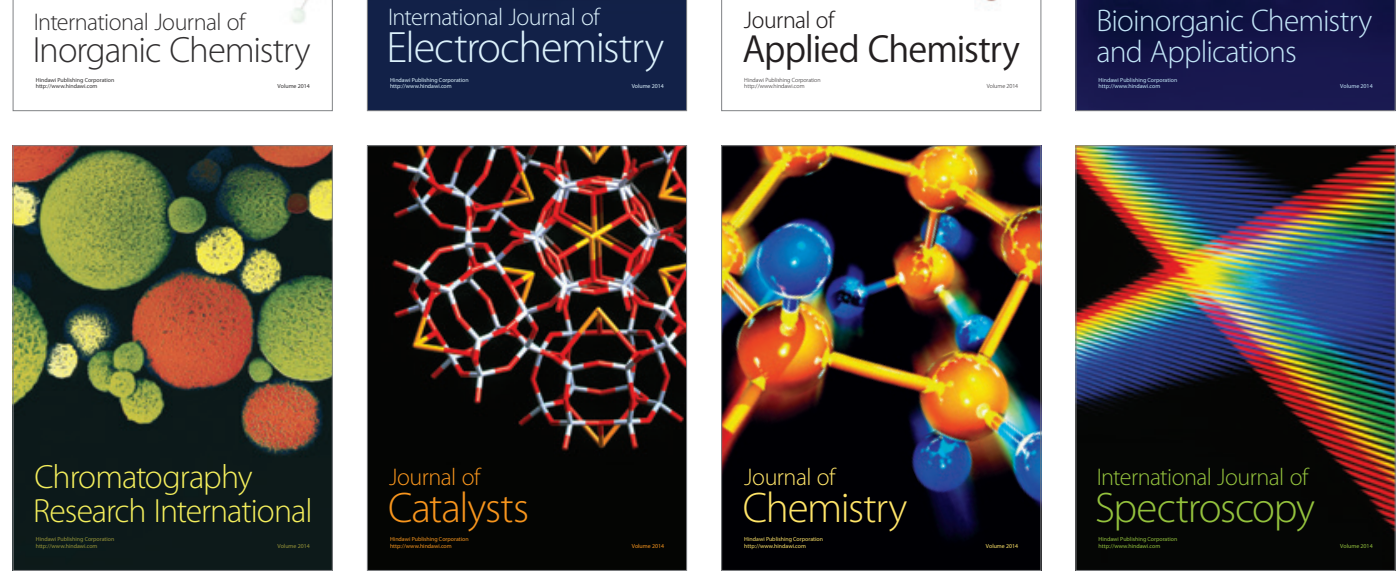